\title{
Sobre juventude e leitura na "idade mídia": implicações para políticas e práticas curriculares
}

\section{On youth and reading in Age Media: implications for curricular policies and practices}

\author{
Maria Luiza Oswald ${ }^{1}$ \\ Sergio Luiz Alves da Rocha
}

\begin{abstract}
RESUMO
Com base em pesquisa institucional, interessada em investigar as relações entre leitura, escrita e mídia, focalizamos neste texto a experiência contemporânea de leitura de jovens estudantes do Ensino Médio de escolas públicas e particulares do Estado do Rio de Janeiro, colocando em xeque o discurso normalmente veiculado pela escola que os representa como não leitores. $\mathrm{O}$ apoio teórico-metodológico da História Cultural e dos Estudos Culturais Latino-Americanos vem nos permitindo entrever, por intermédio de estudos de cunho etnográfico, que o diagnóstico de não leitores aplicado aos jovens refere-se ao seu não submetimento à concepção de leitura mantida intacta pela tradição escolar iluminista que valoriza o livro como único suporte possível de leitura e os clássicos como os mediadores privilegiados da formação do leitor. O contato com os estudantes, seja por meio de observações, seja nas entrevistas e oficinas, tem permitido estranhar este diagnóstico. O que temos percebido é que a relação cotidiana, cada vez mais intensa, dos jovens tanto com as mídias de função massiva, como TV e cinema, quanto com as mídias
\end{abstract}

${ }^{1}$ Doutora em Educação pela Pontifícia Universidade Católica do Rio de Janeiro (PUC-Rio); Professora da Faculdade de Educação e do Programa de Pós-Graduação em Educação da Universidade do Estado do Rio de Janeiro (UERJ); Bolsista do Programa Prociência UERJ/Fundação Carlos Chagas Filho de Amparo à Pesquisa do Estado do Rio de Janeiro (FAPERJ); Coordenadora do Grupo de Pesquisa Infância, Juventude, Educação e Cultura, Brasil. E-mail: moswalduerj@yahoo.com.br

${ }^{2}$ Doutor em Educação pelo Programa de Pós-Graduação em Educação da UERJ; Professor do IFRJ; Membro do Grupo de Pesquisa Infância, Juventude, Educação e Cultura, Brasil. E-mail: sergio.rocha@ifrj.edu.br 
de função pós-massiva, como internet e suas diversas ferramentas, como blogs, orkut, msn, os aproxima da leitura, embora essa aproximação ocorra por intermédio de preferências, e de práticas, diversas das valorizadas pela escola. O presente artigo reflete sobre esses achados, entendendo que eles poderiam ser relevantes ao delineamento de políticas e práticas curriculares concernentes à leitura de jovens estudantes.

Palavras-chave: juventude; contemporaneidade; leitura; escrita.

\begin{abstract}
Based on institutional research, interested in investigate the relations between reading, writing and media, we focus in this text the contemporary experience on reading of young students of Secondary Education in public and private schools of the State of Rio de Janeiro, bringing into question the speech normally propagated by the school which represents them as non-readers. The theoretical and methodological support of the Cultural History and the Latin-American Studies allows perceiving that this diagnosis refers to their refusal of submitting themselves to the conception of reading maintained intact by school's illuminist tradition, which emphasizes the book as the sole reading support and the classics as the privileged mediators of reader's formation. The contact with students, either through observations, either in interviews and workshops, has allowed a surprising diagnosis. What we realized is that the daily contact, unceasingly intense, of young people with the mass media function, such as TV and film, as with the post-mass media function, such as internet and its various tools, such as blogs, orkut, msn, keeps them closer to the reading, although this approach occurs through preferences and practices different from those valued by school. This paper reflects on these findings, arguing that they could be relevant to the design of curricular policies and practices concerning to the reading of young students.
\end{abstract}

Keywords: youth; contemporaneity; reading; writing. 
E, antes que um contemporâneo chegue a abrir um livro, caiu sobre seus olhos um tão denso turbilhão de letras cambiantes, coloridas, conflitantes, que as chances de sua penetração na arcaica quietude do livro se tornaram mínimas.

Walter Benjamin

\section{Introdução}

A discussão sobre a relação do jovem com a leitura tem sido, normalmente, fundamentada na valorização do livro impresso como suporte privilegiado, sendo que no caso da escola, na maioria das vezes, ao se falar em livro, não se está definindo um artefato qualquer. Fala-se em determinados livros considerados representantes da cultura letrada, da cultura erudita ou dos cânones literários ${ }^{3}$ que, por este motivo, seriam capazes de exercer um efeito civilizador sobre seus leitores. A partir daí, temos dois importantes desdobramentos para as análises das práticas de leitura de jovens.

O primeiro é o do argumento ambíguo da crise da leitura ${ }^{4}$ no contexto atual em que o mercado editorial estabelece estratégias de publicação voltadas para o público jovem, reconhecendo seu poder como consumidor. ${ }^{5} \mathrm{O}$ segundo é o do estreitamento daquilo que se define como leitura, limitada ao livro impresso, valorizando-se apenas a leitura literária. Outros gêneros e suportes de leitura permanecem excluídos. Tais desdobramentos produzem a invisibilidade das práticas de leitura de segmentos juvenis, desconhecendo suas particularidades e retirando-lhes a legitimidade.

Dado o caráter limitado e etnocêntrico do debate sobre a relação do jovem com a leitura, não é de estranhar que pouca atenção seja dada ao reconhecimento

${ }^{3}$ Não é nosso interesse entrar na discussão sobre a diferença entre clássicos, ou cânones, e best-sellers, já que o que nos interessa justamente é tanto problematizar a ideia de que os jovens não gostam de ler quanto apontar que a crítica da escola aos supostos efeitos maléficos produzidos pela literatura de entretenimento pode ser suspensa quando ela passa, contemporaneamente, a ser veiculada pelas novas mídias de efeito pós-massivo.

${ }^{4}$ A pesquisa "Retratos da Leitura no Brasil" apontou uma ligeira melhora nos níveis de leitura do brasileiro, em especial entre crianças e jovens até 17 anos de idade.

${ }^{5}$ O Caderno Prosa e Verso, do Jornal O Globo, de 28 de fevereiro de 2009, publicou a matéria intitulada "O poder de fogo do mega-seller", termo que substitui o anterior best-seller a partir da megavendagem de obras como Harry Potter, destinadas aos jovens. Segundo a matéria, "o bruxinho [...] deixou clara a força dos jovens como motor do mercado [editorial]". 
e à análise das leituras efetivamente praticadas pelas gerações mais novas, bem como do contexto mais geral em que estão inseridas, a partir do qual essas leituras ganham sentido. Essa é a preocupação que tem inspirado o Projeto institucional "Educação e Mídia: imagem técnica e cultura escrita", que abrange projetos de iniciação científica, mestrado e doutorado, a investigar práticas de leitura e escrita de crianças e jovens no contexto da "idade mídia". As reflexões do presente texto privilegiaram a interpretação dos dados, produzidos no interior destes projetos, referentes a entrevistas realizadas com jovens de escolas públicas e privadas, focalizando a relação dos mesmos com produtos disponibilizados, na forma impressa e on-line, pela indústria de entretenimento.

O relacionamento com os jovens teve por base as proposições de Bakhtin sobre a natureza da pesquisa nas ciências humanas. Para Bakhtin (1992), “o sujeito como tal não pode ser percebido e estudado a título de coisa porque, como sujeito, não pode, permanecendo sujeito, ficar mudo; consequentemente, o conhecimento que se tem dele só pode ser dialógico." (p. 403). Esse pressuposto levou os participantes do grupo de pesquisa a tomar os princípios do dialogismo e da alteridade como base teórico-metodológica das relações entre pesquisadores e jovens, o que influiu no reconhecimento de que suas práticas de leitura podem estar relacionadas aos modos contemporâneos de ser, de dizer-se, de entreter-se, de agrupar-se, de relacionar-se com o outro das gerações mais novas, motivados, segundo Santaella (2009), pelo novo tipo de sensibilidade corporal, física e mental que a imersão cotidiana no ciberespaço enseja. As contribuições dos estudos culturais latino-americanos (Jesús Martín-Barbero, Néstor Canclini e Guillermo Orozco Gómez) também permitiram aos pesquisadores reduzir a importância atribuída à produção, à difusão e à mensagem de determinados artefatos culturais, buscando compreender o consumo e a recepção desses artefatos com base nas mediações culturais, questionando, assim, a condição de passividade dos jovens leitores.

Cabe dizer que as reflexões aqui desenvolvidas não têm como objetivo criticar os esforços que visam promover o gosto pela leitura literária entre os jovens e, muito menos, deixar de considerar o papel que a escola pode desempenhar na formação de leitores literários. O que ocorre é que nosso envolvimento em estudos que se dedicam a investigar as correlações entre leitura e mídias (massivas e pós-massivas) nos levou à compreensão de que alguns aspectos desse debate deveriam ser discutidos à luz de importantes referenciais teóricos que apontam para as especificidades da contemporaneidade, para a historicidade das práticas de leitura e de escrita e, portanto, para a necessidade de pensar a leitura no interior das práticas culturais. São algumas dessas referências que trazemos nos próximos itens com o objetivo de compartilhar algumas pistas para refletir sobre juventude e leitura. 


\section{Ampliando a discussão teórico-metodológica}

O debate sobre a leitura não deveria ser realizado sem o exame das revoluções tecnológicas e culturais que deslocaram o papel que o livro impresso ocupou progressivamente no Ocidente, principalmente com a sua difusão a partir da invenção da imprensa.

Um importante deslocamento foi constituído com o surgimento da imagem técnica. A proliferação das imagens deslocou a importância da palavra impressa, questionando o logocentrismo e instaurando o debate sobre as possibilidades de a imagem atuar autonomamente como um signo visual, independentemente da linguagem escrita (SANTAELLA; NÖTH, 1982). Entretanto, a partir das mídias massivas, cinema e, particularmente, a televisão, constitui-se uma resposta a esse questionamento que derivou numa crítica ao caráter superficial da imagem, ${ }^{6}$ com a consequente valorização do texto escrito.

Foi baseada nesse posicionamento que a escola, inicialmente, não viu com bons olhos a tela da televisão, assim como hoje, em muitos casos, resiste às telas do computador, da internet e dos celulares. Prescindindo das competências que a leitura do impresso exige, divulgando suas mensagens através das imagens e do som, essas telas supostamente colaboram para o abandono da leitura do livro, prática de leitura que a escola considera como legítima.

Para Martín-Barbero, desde o surgimento da imprensa constituiu-se uma cultura do texto que estruturou uma forma específica de "[...] comunicação exclusiva entre os adultos, instaurando uma marcada segregação entre adultos e crianças [...]" (MARTÍN-BARBERO; REY, 2004, p. 55). A cultura do texto impresso criou um mundo de separações: das identidades, das etapas da aprendizagem, dos dispositivos de controle social da informação.

A utilização da idade como critério definidor da infância permitiu que no contexto escolar fosse estabelecida uma dupla relação: “[...] entre a linearidade do texto escrito e o desenvolvimento escolar - o avanço intelectual caminha

${ }^{6}$ Sem fazer apologia das transformações da técnica, em curso já na década de 30, Benjamin afirmava, a respeito da influência das técnicas de reprodução - especialmente o cinema - na constituição da percepção humana, que "[...] no interior dos grandes períodos históricos, a forma de percepção das coletividades humanas se transforma ao mesmo tempo em que seu modo de existência [...]" (BENJAMIN, 1994, p. 169). Com isso, o autor chamava atenção para a constituição de uma cultura cada vez mais centrada na imagem e na crescente disponibilidade de meios técnicos de mediação das relações sociais, sem percebê-los como simples deformação ou degeneração de formas mais nobres de percepção da realidade. 
paralelo com o progresso na leitura - e entre este e as escalas mentais da idade". (MARTÍN-BARBERO; REY, 2004, p. 57).

Desde então, a escola passou a estimular um modelo "mecânico e unidirecional" de leitura. Um modelo de leitura passiva, cuja correspondência pode ser estabelecida com aquela instituída há muito tempo pela Igreja. Da mesma forma que os clérigos do passado, os professores também afirmam a existência de uma leitura unívoca. À leitura do aluno não cabe outra possibilidade senão a de ser percebida como simples eco, desaparecendo qualquer possibilidade de lhe abrir o espaço da criatividade. (MARTÍN-BARBERO; REY, 2004, p. 57).

Este modelo não é mais sustentável em função das modificações nos processos e nas técnicas de comunicação que ocorrem nos dias atuais. Hoje estão disponíveis inúmeros meios para armazenar e acessar aquilo que antes somente o livro disponibilizava. Os indivíduos convivem com uma multiplicidade de "[...] textos, relatos e escrituras (orais, textuais, visuais, musicais, audiovisuais, telemáticos) [...]" (MARTÍN-BARBERO; REY, 2004, p. 58). Esta heterogeneidade atua de modo a transformar os modos de ler, representando uma reorganização das leituras e das escritas.

A escola está diante de um ecossistema comunicativo que, deslocando o privilégio do livro como eixo tecnopedagógico, constitui o entorno educacional difuso e descentrado, como uma marca da atualidade. O saber, antes restrito espacialmente e limitado a determinados suportes e figuras sociais, escapa de uns e de outras. Escola, livro, professores, todos são deslocados e desafiados por este novo contexto (MARTÍN-BARBERO; REY, 2004, p. 59).

Seria, então, necessário que a escola modificasse seu modelo e sua práxis de comunicação, favorecendo a passagem "de um modelo linear - que encadeia unidirecionalmente, graus, idades e pacotes de conhecimento - a outro descentrado e plural, cuja chave é o 'encontro' do palimpsesto e do hipertexto." (MARTÍN-BARBER; REY, 2004, p. 62-63).

Martín-Barbero dimensiona o enorme desafio que é hoje proposto à escola e aos educadores. Caberia a eles substituir o discurso moralista que valoriza a cultura do texto, e os aspectos a ela relacionados, por um compromisso ético que, reconhecendo "[...] a tecnicidade midiática como dimensão estratégica da cultura [...]" (MARTÍN-BARBERO; REY, 2004, p. 63), reconheça também a necessidade de a escola estar inserida neste processo de mudança que vivemos. Isso não significa que a escola deveria abrir mão do uso do livro. Este continuaria a ser fundamental ao que o autor define como primeira alfabetização formal. Mas esta alfabetização primeira só adquire sentido na medida em que fornece as bases para uma segunda alfabetização. Esta deveria tornar o indivíduo capaz de interagir com as múltiplas escrituras disponíveis ao nosso redor. (MARTÍN-BARBERO; REY, 2004, p. 62). 
De acordo com outro autor, Orozco Gómez, caberia à escola a ampliação daquilo que se entende normalmente por alfabetização, limitada a linguagens e meios específicos. Dever-se-ia pensá-la como alfabetização cultural, reconhecendo neste processo as complexas possibilidades de interlocução existentes no mundo contemporâneo que exigem do indivíduo habilidades comunicacionais variadas. Só uma alfabetização concebida deste modo permitiria aos sujeitos participarem de forma ativa do intercâmbio social. (OROZCO GÓMEZ, apud BACCEGA, 2003, p. 77).

Nessa mesma direção encaminham-se as reflexões de Nestor García Canclini. Ele afirma que os jovens de hoje adquirem, através da combinação entre conhecimento e entretenimento, disponibilizados pelas telas extracurriculares, uma formação muito mais geral. Reconhecendo as relações entre as diversas possibilidades comunicacionais, ele afirma que "também se aprende a ler e a ser espectador sendo telespectador e internauta. Leitores, espectadores e internautas". (CANCLINI, 2008, p. 24).

Canclini nos questiona sobre a possibilidade de considerarmos a leitura de modo isolado, sem avaliar as suas relações com outras práticas que, como o acesso à internet, dependem do ato da leitura, bem como do da escrita, ou mesmo em relação à televisão, que pode servir também como estimuladora de leitura. ${ }^{7}$

A análise de Canclini já nos direciona para o segundo deslocamento, cujo exame deveria subsidiar o debate sobre práticas contemporâneas de leitura e de escrita. As mídias de função pós-massiva, como internet e suas diversas ferramentas como blogs, wikis, podcasts, redes P2P, softwares sociais e os telefones celulares, além de agregarem a imagem ao texto, superam as mídias de função massiva por serem mais interativas do que informativas. Enquanto na estrutura massiva a informação flui do polo da emissão para o da recepção, que será mais ou menos crítica e criativa dependendo das mediações, com a emergência das mídias de função pós-massiva libera-se a emissão e ocorre a liberação da palavra, o que permite "a qualquer pessoa, e não apenas empresas de comunicação, consumir, produzir e distribuir informação sob qualquer formato em tempo real [...] sem ter que movimentar grandes volumes financeiros ou ter que pedir concessão a quem quer que seja" (LEMOS; LÉVY, 2010, p. 25. Grifos no original).

Assistimos, assim, a um verdadeiro paradoxo, pois se no ambiente escolar os professores reclamam que os alunos não querem ler e muito menos escrever,

${ }^{7}$ Já é comum que algumas das adaptações de obras literárias pela televisão acabem impulsionando a venda dos livros homônimos. Podemos encontrar em Reimão (2001) uma análise das relações entre o mercado editorial e as adaptações para televisão. 
fora da escola, o acesso à internet em casa, ou via dispositivos móveis (telefones celulares, redes $3 \mathrm{G}, w i-f i)$, estimula crianças e jovens não só a lerem e a escreverem num ritmo intenso e acelerado, como também incentiva a circulação de leituras e escritas por intermédio da conexão em redes abertas, como ocorre nas redes sociais: Facebook, MySpace, Orkut, NING, Twitter. ${ }^{8}$

Mesmo nas escolas públicas que constituem campos de pesquisa, em que os alunos são economicamente menos favorecidos, são visíveis as referências ao uso de e-mails, do msn e do orkut, de blogs e ao acesso a sites diversos. Muitas dessas práticas viabilizam o acesso dos alunos à leitura de obras que, caindo no gosto dos jovens, servem de pretexto à constituição de redes de leitores que não só as discutem, mas também as reelaboram, seja individual, seja coletivamente.

Daí a importância de qualificarmos a ideia de que os jovens não leem. Um bom início seria a ampliação daquilo que consideramos leitura, o que possibilitaria também o reconhecimento de que tal prática poderia dar-se a partir de diferentes suportes, além do livro.

Um autor que nos ajuda a enfrentar esse desafio é Roger Chartier. Em vários de seus trabalhos (1994, 2001, 2002, 2003, 2007), esse autor produziu um conjunto de análises que desnaturalizam as preconcepções sobre o livro, ${ }^{9}$ a escrita e a leitura, chamando atenção para a importância de se analisar o artefato livro e as práticas de leitura e escrita a partir de uma perspectiva histórica e do ponto de vista das práticas concretas. Para Chartier, a leitura deve ser analisada numa perspectiva relacional para que não se incorra no erro de considerar que existe apenas uma forma de leitura. Não é o texto que determina soberanamente o tipo de compreensão que se tem da mensagem. As condições concretas de leitura determinam formas também distintas de sua realização. Diferentes "comunidades de leitores" e "tradições de leitura" ensejam distintas relações com a mensagem impressa no livro, bem como com os diferentes significados que tanto o livro como a leitura têm para leitores diversos (CHARTIER, 1994, 2001). As normas e convenções de leitura determinam os usos legítimos do livro, as formas de ler e os procedimentos utilizados na interpretação de acordo com as distintas comunidades de leitores (CHARTIER, 1994, p. 13).

${ }^{8}$ É a própria ideia de consumo que sofre uma alteração. O consumo torna-se cada vez mais o lugar da produção de sentido. Ele deixa de ser considerado como o simples esgotamento, uso ou fruição de um bem ou de um produto cultural.

${ }^{9}$ De acordo com o autor, aquilo que chamamos de livro, ou leitura, por exemplo, não significa a mesma coisa em épocas diferentes. Em relação ao papel do livro, é preciso considerar o contexto de sua consolidação como suporte material privilegiado da escrita, sendo fundamental entender as transformações provocadas pela substituição do volumen pelo códex e, posteriormente, a importância da produção tipográfica que substitui a dos escribas. (CHARTIER, 2003. p. 29-36). 
Compreender o processo da longa história da escrita e de seus suportes é fundamental para que possamos refletir sobre os diferentes tipos de leitores e produtores de textos que coexistem. O leitor do livro, que escreve em cadernos, estabelece relações com a leitura e a escrita que são diversas daquelas que o usuário do texto hipermídia estabelece com as mesmas (SANTAELLA, 2009, p. 11). Chartier considera essa última revolução mais radical do que a proporcionada por Gutemberg, já que não se limitou a modificar apenas a técnica de reprodução do texto, mas alterou também as estruturas e as formas do suporte. (CHARTIER, 2002, p. 33).

Entre as modificações citadas pelo autor, nos interessa chamar atenção para o fim de uma restrição, até então imperativa: aquela que dizia respeito às impossibilidades de intervenção do leitor no livro impresso. A partir do século XVI, com a impressão, o objeto impresso passou a impor a sua forma, cabendo ao leitor limitar a sua escritura aos espaços em branco do impresso. Essa limitada participação do leitor modifica-se com o texto eletrônico, pois ele dilui a distinção, antes muito clara, entre o ato da escrita do autor e ato de leitura do leitor. Assim, "o leitor torna-se um dos atores de uma escritura a muitas mãos ou, ao menos, encontra-se na posição de constituir um texto novo a partir de fragmentos livremente recortados e reunidos". Podendo intervir a qualquer momento nos textos, o leitor pode "modificá-los, reescrevê-los, torná-los seus" (CHARTIER, 2002, p. 42-43). O texto eletrônico esmaece as fronteiras entre a leitura como atividade de mero consumo por parte do leitor e a escrita como ato produtivo do escritor, diluindo a própria possibilidade de pensar nas obras produzidas dessa forma como sendo o resultado de um ato criador individual, pondo em suspenso a própria noção de copyright.

Outra dicotomia rígida quebrada pelas formas eletrônicas de apresentação de textos é aquela que opõe de um lado livro/escrita/leitura e, de outro, tela/ imagem. Se as telas da televisão e do cinema excluíam quase que totalmente a presença do texto, as novas telas eletrônicas trazem, além do texto, as imagens, exigindo uma reflexão mais apurada sobre a relação mecânica entre tela e declínio da leitura. (CHARTIER, 2002, p. 105-106).

A partir da análise desses autores, podemos perceber que as diferentes telas reconfiguraram o significado e o papel da leitura na contemporaneidade. O texto, antes fixado prioritariamente no livro impresso, passou a ser disponibilizado em diferentes suportes, podendo ser reelaborado. Ao mesmo tempo, as novas formas de comunicação possibilitaram a consolidação de comunidades de jovens formadas em torno do consumo/produção de diversos artefatos culturais. 


\section{Jovens: leitura, escrita, tecnologia e indústria de entretenimento}

Será que as indicações anteriores não se constituem como meras generalidades? É mesmo possível pensar em relações propositivas entre os diferentes meios de comunicação de forma que a leitura, mesmo quando considerada de modo diferente, continue a existir, podendo ser uma prática potencializada? É sobre essas questões que os diferentes projetos do grupo de pesquisa vêm se debruçando.

Apresentamos a seguir alguns achados de nossas pesquisas referentes às especificidades das práticas de leitura e escrita de jovens fanfiqueiros e de jovens otakus. ${ }^{10}$

\section{Práticas de leitura e escrita de jovens fanfiqueiros}

Abreviatura de Fan Fiction, uma fanfic é uma história criada por um fã de determinada obra e/ou personagem (Harry Potter, Cavaleiros do Zodíaco, Crepúsculo etc.) aos quais tem acesso seja individualmente, por intermédio das mídias massivas - livros, filmes, desenhos animados -, seja coletivamente, por intermédio da conexão em rede - msn, blogs, orkut, wikipedia, sites etc. As histórias são escritas tendo por base o universo ficcional da obra ou do personagem em questão, que é reapropriado pelo(s) fã(s) em novas histórias. As fanfics não têm por objetivo obter lucro. Não sendo comercializadas, tais produções são geralmente toleradas pelos proprietários dos direitos autorais das histórias originais.

Tais histórias ganharam uma dimensão diferente a partir das possibilidades abertas pela internet, passando a ser publicadas em diferentes e variados sites. Alguns deles passaram a especializar-se em determinadas personagens, enquanto outros abordam histórias de várias personagens. ${ }^{11}$ Neles há um conjunto de normas que devem ser observadas por aqueles que escrevem as histórias.

${ }^{10} \mathrm{O}$ termo fanfiqueiro se refere a pessoas que produzem fan fictions e o termo otaku a fãs dos produtos da indústria de entretenimento japonesa: mangás (histórias em quadrinhos), animes (desenhos animados) e video games.

${ }^{11}$ Existe uma enorme quantidade e variedade de sites onde são postadas essas histórias. Uns recebem e divulgam histórias criadas a partir de diferentes produtos: filmes, livros, bandas musicais, desenhos, animes e séries de TV, games etc., como <http://www.fanfiction.net $>$. Outros 
Nosso contato mais próximo foi com um grupo de jovens, frequentadores de uma escola particular do Rio de Janeiro, que liam e/ou produziam fanfics, tendo como motivação o universo ficcional da obra de J. K. Rowling, constituído pelos livros que narram as aventuras do aprendiz de bruxo Harry Potter. Segundo seus depoimentos, eles haviam lido todos os livros de Harry Potter ${ }^{12}$ publicados no Brasil, além de terem visto todos os filmes da série. Somados, estes livros possuem aproximadamente 2.695 páginas, sendo que os livros Harry Potter e o cálice de fogo e Harry Potter e o enigma do príncipe têm, respectivamente, 583 e 510 páginas cada um, e o volume Harry Potter e a Ordem da Fênix possui 704 páginas. Mesmo depois de terem visto os filmes, os livros continuam sendo uma fonte inesgotável de informações para estes jovens, juntamente com a leitura das fanfics escritas por outros jovens e publicadas na internet. Em alguns sites, é possível encontrar algumas dessas fanfics com mais de 250 páginas.

$\mathrm{O}$ que se percebeu no caso específico deste grupo de jovens é que o interesse pela leitura das fanfics foi determinado por uma complementaridade de práticas, envolvendo tanto a recepção de imagens (cinema) quanto a leitura do texto realizada nos suportes impresso e eletrônico. Essa mesma relação de concorrência pode ser observada no modo pelo qual o grupo produz as fanfics. Elas não são digitadas diretamente no computador. São escritas primeiro em cadernos especialmente destinados a este tipo de atividade. Contrariando o senso comum, que sustenta que a juventude não escreve, esse grupo dedica algumas horas de seu dia a produzir de forma manuscrita suas histórias, que são posteriormente digitadas e publicadas em sites, tornando-se acessíveis a outros leitores, bem como servindo de inspiração a outros autores. O próprio processo de criação implica algum tipo de discussão com os colegas, não sendo um processo totalmente autoral, tal como ocorre nas redações ou nos trabalhos escolares que produzem tanto mal-estar nos alunos.

Alguns sites não publicam as fanfics sem que elas sejam antes lidas e comentadas pelos chamados beta-readers. Nos sites que utilizam os beta-readers, eles desempenham diversas tarefas, entre as quais: verificar se a fanfic é uma cópia da obra original, corrigir erros de português e até ajudar os autores nas

publicam apenas histórias escritas a partir de bandas de música, como $<$ http://fanficaddiction.com. br $>$. Alguns abordam histórias escritas somente a partir de determinadas séries de livros, como a série Harry Potter no site $<$ http://fanfic.potterish.com/>. Há ainda outros que só utilizam como base das histórias os desenhos animados, como o site $<\mathrm{http}$ ://fanficobsession.com.br/>.

${ }^{12}$ Os livros da série, publicados em português pela editora Rocco, são respectivamente: Harry Potter e a pedra filosofal (1997), Harry Potter e a câmara secreta (2000), Harry Potter e o prisioneiro de Azkaban (2000), Harry Potter e o cálice de fogo (2001), Harry Potter e a Ordem da Fênix (2003), Harry Potter e o enigma do principe (2005) e Harry Potter e as reliquias da morte (2007). 
suas dificuldades de escrita. Algumas das fanfics publicadas podem ser interativas, feitas a partir de scripts que possibilitam inserção de respostas a perguntas previamente feitas pelo seu autor. Há também a possibilidade de os leitores expressarem suas opiniões sobre o que leram, influenciando a escrita futura da história, já que muitas são escritas em vários capítulos.

As práticas relacionadas ao consumo, recepção e produção de fanfics permitem relativizar a ideia de que os jovens não gostam de ler e de escrever. Ao mesmo tempo, as fanfics apontam para a necessidade de uma maior reflexão sobre a relação de causa e efeito entre o surgimento de novas tecnologias e o declínio da leitura e da escrita (o que poderia ser percebido com uma simples visita aos sites de relacionamento, onde há uma intensa troca de mensagens). Alguns dos jovens ampliaram inclusive seu escopo de leitura a partir de Harry Potter, lido no suporte impresso ou digital.

Outro aspecto importante são as redes de sociabilidade que são estabelecidas para além do mundo virtual, como é o caso da consolidação de grupalidades juvenis que se constituem tanto dentro da escola como fora dela. Nesse sentido, o interesse pela leitura e escrita das fanfics pode caminhar de contatos virtuais para uma amizade presencial (essas expressões são aqui usadas com nenhuma conotação valorativa, apenas como recurso descritivo), constituindo o que Chartier $(1994,2001)$ denomina de comunidade de leitores.

As comunidades reunidas em torno de Harry Potter muitas vezes são constituídas nos chamados potterencontros. Nesses encontros, a experiência dos jovens com a leitura deixa de ser uma experiência exclusivamente solitária, constituindo-se também em oportunidade para trocas diversas e estabelecimento de amizade e de novos conhecimentos.

Esse tipo de encontro ocorre também com fãs de outros produtos da indústria de entretenimento, como é o caso dos animencontros, que reúnem os otakus.

\section{Práticas de leitura de jovens otakus}

Os mangás são revistas em quadrinhos que diferem das ocidentais pelas seguintes especificidades: linguagem visual baseada no cinema, com proliferação de efeitos visuais para transmitir ideia de movimento e de emoções; desenho em preto-e-branco; personagens apresentados de forma estilizada por intermédio de olhos excessivamente grandes e cabelos com formatos não convencionais; as histórias são apresentadas em capítulos, descrevendo o crescimento e as transformações dos personagens em seu dia a dia, o que envolve o leitor com as 
sagas dos diferentes heróis e heroínas dos mangás que, ao contrário dos heróis das comics americanas, são imprevisíveis, além de próximas do que ocorre na vida cotidiana dos e das jovens.

O projeto institucional buscou, baseado em uma ampliação do conceito de leitura (Chartier) e na necessidade de reconhecer a legitimidade das práticas juvenis (Canclini, Martín-Barbero), entender as razões da grande penetração dos mangás entre jovens cariocas. ${ }^{13}$ A intensidade dessa prática contrastava com a ideia de que os jovens não gostam de ler.

Ao enveredar por esse universo de leitura dos jovens, considerada por nós como prática legítima, acabamos por entrar em contato com os animencontros, eventos presenciais que reúnem fãs da indústria de entretenimento japonesa que agrega, além dos mangás, os animes (desenhos animados) e os video games. Foi nesses encontros que travamos contato com jovens otakus, frequentadores de escolas públicas e privadas, que acabaram se constituindo sujeitos de nossas pesquisas.

Que questões relativas a práticas juvenis contemporâneas de leitura o contato com otakus nos trouxe?

Seus depoimentos chamaram a atenção para o papel mediador da imagem técnica nas novas formas de ler e de produzir conhecimento e cultura. Segundo eles, a linguagem cinematográfica dos mangás "faz o texto andar", ao contrário do livro, em que o texto "fica parado, naquele bando de linha e de letra". "Ler mangá é como ver cinema", como nos disse um dos entrevistados. Essa preferência pelo "texto que anda" não é uma mera questão de gosto. Ela ocorre em função da intensa relação dos sujeitos com as visualidades tecnificadas que inundam contemporaneamente o cotidiano, e que lhes apresentam o mundo de forma volátil e fragmentada, incoerente com a leitura linear e sequencial do livro. No entanto, isso não significa que os jovens entrevistados não lessem textos impressos. ${ }^{14}$ Alguns deles adquiriam tamanho fascínio pelo universo da cultura japonesa que acabavam buscando maiores informações sobre essa cultura em livros buscados na biblioteca da escola, na internet e mesmo a partir de sugestões de seus professores.

Os jovens, também neste caso, deixaram clara a relação entre o gosto pelos mangás e o acesso aos diferentes suportes comunicacionais. Foi possível veri-

${ }^{13}$ Os animencontros ocorrem em todo o país. O maior deles, o Anime Friends, é realizado anualmente em São Paulo, com a duração de 6 dias. Em 2008 pudemos acompanhar um desses encontros que reuniu, de acordo com os organizadores, 70 mil jovens no último dia do evento.

${ }^{14} \mathrm{Em}$ um dos encontros pudemos fotografar uma jovem caracterizada como um dos personagens de mangá, lendo um livro de Honoré de Balzac, Le Père Goriot, em francês. 
ficar que alguns jovens se tornaram leitores de mangá a partir da assistência de animes e do contato com os jogos eletrônicos. Mais uma vez, como nas fanfics, vemos que não há relação de exclusão entre os diferentes suportes. Os próprios mangás e os animes também aparecem nos sites especializados de fanfics como universos a partir dos quais várias novas histórias são escritas, bem como são temas de uma infinidade de sites na internet que disponibilizam uma grande quantidade de informação escrita.

Outro elemento comum entre otakus e fanfiqueiros foi o estabelecimento das redes de sociabilidade em torno do consumo e da recepção de mangás e fanfics. Embora leiam sozinhos as HQs, é no plano coletivo que essa prática se torna significativa, através da troca de revistas, das competições sobre quem sabe mais sobre a saga dos heróis e heroínas, dos debates em torno dos valores humanos expressos nos enredos. Essas redes de sociabilidade acabam por ser transferidas para os animencontros, constituindo grupos de amizade que, muitas vezes, transcendem tais encontros.

\section{Concluindo...}

Tanto as fanfics como os mangás apontam a importância que os jovens dão à experiência de compartilhar suas leituras. Ao modelo de leitura clássico que supõe o leitor individual isolado em seu espaço, fazendo uma leitura silenciosa, essas novas práticas contrapõem o desejo de constituir uma experiência que possibilite a troca. A natureza intermediada da relação dos jovens com a leitura permite relativizar sua pretensa passividade em relação ao consumo cultural. Na mesma direção, Martín-Barbero (2002) aponta que a recepção é um lugar de interações e de produção de sentidos que envolve não apenas as mensagens e os aparatos, mas outros atores sociais.

Também foi possível perceber, a partir do contato com essas práticas, e de sua interpretação com base nos autores citados ao longo do texto, que muitas das avaliações sobre as dificuldades dos jovens com a leitura na escola não podem ser imputadas, de maneira tão rápida e mecânica, às interações com as novas tecnologias. Por outro lado, também foi possível estranhar a má vontade que, muitas vezes, a escola demonstra para com os chamados best-sellers.

O que temos observado é que a relação cotidiana, cada vez mais intensa, dos jovens tanto com as mídias de função massiva, como TV e cinema, quanto com as mídias de função pós-massiva, como internet e suas diversas ferramentas, como blogs, orkut, msn, os aproxima da leitura, embora essa aproximação 
ocorra por intermédio de preferências, e de práticas, diversas das valorizadas pela escola que, ainda hoje, na maioria das vezes, valoriza preferencialmente a leitura canônica, desenvolvida individualmente, que, supostamente, aperfeiçoaria a linguagem e promoveria a consciência crítica do leitor.

Os jovens sujeitos das pesquisas demonstraram sua preferência pelas leituras colocadas em circulação pela cultura de massas com o apoio das mídias, como é o caso do fenômeno de vendas Harry Potter e dos mangás, e que são consumidas coletivamente pelas comunidades de internautas que proliferam na web. Este consumo coletivo, que configura as "comunidades interpretativas", tem nos possibilitado relativizar a crítica ao efeito de evasão e de deserção supostamente ocasionado pelas obras de consumo.

Discutidas e reelaboradas de forma compartilhada, presencialmente ou via internet, essas obras são, muitas vezes, responsáveis pela formação de leitores que são simultaneamente produtores de cultura.

Concluindo, gostaríamos de chamar a atenção daqueles que se ocupam da educação e da formação do jovem, na escola ou fora dela, para a necessidade de se reconhecer suas práticas culturais, percebendo nelas também o espírito de uma determinada época. Relativamente à escola, sem essa percepção ela corre o risco de se afastar ainda mais de seus alunos. Se à escola cabe determinado compromisso como transmissora de uma certa herança cultural, avaliada como significativa para as futuras gerações, cabe a ela reconhecer as modificações que estão ocorrendo no mundo em que vivem os jovens para poder tornar sua atuação apropriada ao presente.

\section{REFERÊNCIAS}

AMORIM, Galeno (Org.). Retratos da leitura no Brasil. São Paulo: Imprensa Oficial/ Instituto Pró-Livro, 2008.

BACCEGA, Maria A. Televisão e escola: uma mediação possível? São Paulo: SENAC, 2003.

BAKHTIN, Mikhail. Estética da criação verbal. São Paulo: Martins Fontes, 1992.

BENJAMIN, Walter. Guarda-livros juramentado. In: . Obras escolhidas II: Rua de mão única. São Paulo: Brasiliense, 1987. p. 27-29.

. A obra de arte na era de sua reprodutibilidade técnica. In: . Obras esco-

lhidas I: Magia e técnica, arte e política: ensaios sobre literatura e história da cultura. 7. ed. São Paulo: Brasiliense, 1994. p. 165-196. 
BERTOL, Raquel. "O poder de fogo do mega-seller". O Globo. Rio de Janeiro, 28 de fevereiro de 2009. Caderno Prosa e Verso.

CANCLINI, Nestor García. Consumidores e cidadãos: conflitos multiculturais da globalização. 5. ed. Rio de Janeiro: Editora da UFRJ, 2005.

. Leitores, espectadores e internautas. São Paulo: Iluminuras, 2008.

CHARTIER, Roger. A ordem dos livros. Leitores, autores e bibliotecas na Europa entre os séculos XIV e XVIII. Brasília: Universidade de Brasília, 1994.

. Cultura escrita, literatura e história: conversas de Roger Chartier com Carlos Aguirre, Jesús Anaya Rosique, Daniel Goldin e Antonio Saborit. Porto Alegre: Artmed, 2001.

. Os desafios da escrita. São Paulo: Editora UNESP, 2002.

. Formas e sentido: entre distinção e apropriação. Campinas: Mercado de Letras/ Associação de Leitura do Brasil (ALB), 2003.

. Inscrever e apagar. Cultura escrita e literatura (séculos XI-XVIII). São Paulo: Editora ENESP, 2007.

DAUSTER, Tania. A fabricação de livros infanto-juvenis e os usos escolares - o olhar dos editores. In: SEMINÁRIO BRASILEIRO SOBRE O LIVRO E HISTÓRIA EDITORIAL, 1., 2008. [Trabalho apresentado]. Disponível em: $<$ http://www.livroehistoriaeditorial.pro. br/primeiroseminario/pdf/taniadauter.pdf > . Acesso em: 10/12/2008.

FAILLA, Zoara. Os jovens, leitura e inclusão. In: AMORIM, Galeno (Org.). Retratos da leitura no Brasil. São Paulo: Imprensa Oficial/Instituto Pró-Livro, 2008. p. 95-107.

LEMOS, André; LÉVY, Pierre. O futuro da internet: em direção a uma ciberdemocracia planetária. São Paulo: Paulus, 2010.

MACHADO, Arlindo. A televisão levada a sério. 3. ed. São Paulo: Editora Senac São Paulo, 2003.

MARTÍN-BARBERO, Jesus. América Latina e os anos recentes: o estudo da recepção em comunicação social. In: SOUSA, Mauro W. Sujeito, o lado oculto do receptor. São Paulo: Brasiliense, 2002.

. Dos meios às mediações: comunicação, cultura e hegemonia. 2. ed. Rio de Janeiro: Editora da UFRJ, 2003.

; REY, Germán. Os exercícios do ver: hegemonia audiovisual e ficção televisiva. 2. ed. São Paulo: Sêneca, 2004.

MERCIER, Paul. A história da antropologia. Rio de Janeiro: Livraria Eldorado, 1974.

REIMÃO, Sandra. Os best-sellers de ficção no Brasil 1990-2000. In: CONGRESSO INTERNACIONAL DE COMUNICAÇÃO, 24., Campo Grande, 2001. [Trabalho apre- 
sentado]. Disponível em: <http://www.intercom.org.br/papers/nacionais/2001/papers/ NP4REIMAO.pdf>. Acesso em: 01/01/2009.

SANTAELLA, Lucia. Navegar no ciberespaço: o perfil cognitivo do leitor imersivo. 3. ed. São Paulo: Paulus, 2009.

; NÖTH, Winfried. Imagem: cognição, semiótica, mídia. São Paulo: Iluminuras, 2008.

Texto recebido em 10 de março de 2011.

Texto aprovado em 06 de setembro de 2012. 